\title{
Estudo de caso sobre a aplicação da metodologia Scrum em uma startup tecnológica de Minas Gerais
}

\author{
Case study on the application of Scrum methodology in a technology startup of Minas Gerais \\ Estudio de caso sobre la aplicación de la metodología Scrum en una startup tecnológica de Minas
}

Gerais

Recebido: 17/02/2021 | Revisado: 23/02/2021 | Aceito: 28/02/2021 | Publicado: 08/03/2021

\author{
Geúno Bruno Vieira Soares \\ ORCID: https://orcid.org/0000-0001-8506-3403 \\ Universidade Federal de Itajubá, Brasil \\ E-mail: geunobruno@gmail.com \\ Tábata Fernandes Pereira \\ ORCID: https://orcid.org/0000-0002-6754-7815 \\ Universidade Federal de Itajubá, Brasil \\ E-mail: tabatafp@unifei.edu.br
}

\begin{abstract}
Resumo
Com a globalização, as formas de se gerenciar projetos tem se aprimorado de maneira constante. Nesse contexto, surge o Manifesto Ágil que permitiu a criação de diversas metodologias ágeis que possuem características variadas como dinamismo, adaptabilidade e produtividade, sendo o Scrum uma delas. Dessa maneira, o objetivo deste trabalho consiste em verificar o impacto deste framework em todas as áreas de Lean Startup, desde o Marketing até o Desenvolvimento, e a influência na produtividade e qualidade das atividades executadas dentro de uma startup mineira. Para se atingir este objetivo, foram realizadas entrevistas semiestruturada, em que se pode analisar os impactos da metodologia na execução das tarefas. Ao final do trabalho, pode-se observar pontos positivos gerados pela implantação da metodologia, como organização e priorização, e também foram apontadas as dificuldades encontradas, como gestão do tempo e priorização.
\end{abstract}

Palavras-chave: Metodologia ágil; Qualidade; Produtividade; Scrum; Startup.

\begin{abstract}
The ways of managing projects have been constantly improving because of globalization. In that context, the Agile Manifesto emerged, which allowed the creation of several agile methodologies that have varied characteristics such as dynamism, adaptability and productivity, Scrum being one of them. Therefore, the objective of this work is to verify the impact of this framework in all areas of a Lean Startup, which has a journey designed in Marketing and Sales, going through the Customer Experience, up to the Products and Development areas, and also, verifying terms of productivity and quality of activities carried out in this startup located in the state of Minas Gerais. In order to achieve this objective, semi-structured interviews were carried out in which it is possible to analyze the impacts of the methodology in the execution of the tasks of all employees involved. At the end of the study, one can see positive points generated by the implementation of the methodology, such as organization and prioritization, and the difficulties encountered, such as time management, were also pointed out.
\end{abstract}

Keywords: Agile methodology; Quality; Productivity; Scrum; Startup.

\section{Resumen}

Con la globalización, las formas de gestionar proyectos han mejorado constantemente. En este contexto surgió el Manifiesto Ágil, que permitió la creación de diversas metodologías ágiles que tienen características variadas como dinamismo, adaptabilidad y productividad, siendo Scrum una de ellas. Así, el objetivo de este trabajo es verificar el impacto de este framework en todas las áreas de un Lean Startup, que tiene un recorrido iniciado en Marketing y Ventas, pasando por la Experiencia del Cliente, a las áreas de Productos y Desarrollo, y la influencia en productividad y calidad de las actividades realizadas dentro de esta startup ubicada en el estado de Minas Gerais. Para lograr este objetivo, se realizaron entrevistas semiestructuradas en las que es posible analizar los impactos de la metodología en la ejecución de las tareas de todos los empleados involucrados. Al final del estudio, podemos ver los puntos positivos generados por la implementación de la metodología, como la organización y priorización, y también se señalaron las dificultades encontradas, como la gestión del tiempo y la priorización.

Palabras clave: Metodología ágil; Calidad; Productividad; Scrum; Startup. 


\section{Introdução}

Ao longo do tempo, a tecnologia da informação tem se desenvolvido cada vez mais e gerado impactos diretos em diversos aspectos pessoais e profissionais (Laurindo, Shimizu, Carvalho, \& Rabechini, 2001). Dentro das organizações, os gestores dos projetos adquirem a incumbência de adaptar os seus processos ao meio em que estão inseridos para que as atividades executadas cumpram os diversos requisitos exigidos. Dentre eles, o fornecimento de resultados de máxima qualidade, a geração de valor direto para a empresa e a retenção de condições para que a competitividade se mantenha em alta.

Dessa maneira, com a aplicação da Gestão de Projetos (GP), Marques e Plonski (2011) citam como dificuldade a entrega de projetos que atendam às especificações planejadas e que atinjam aos objetivos de negócio. Então, com o intuito de entender e ressaltar as prioridades necessárias para que os processos sejam executados com clareza e sucesso, os estudos na área têm aumentado de maneira exponencial, fazendo com que a busca de soluções para que essa gestão possa ser realizada com êxito seja contínua (Martins, Moura, \& Mesquita, 2011).

Em muitos projetos, são aplicadas metodologias tradicionais na execução das ações. Essas são consideradas estáveis, orientadas a planejamentos a longo prazo e são utilizadas em situações em que os requisitos podem ser previstos e que dificilmente terão grandes alterações durante a realização das tarefas propostas.

Entretanto, quando tais aspectos não estão presentes, utilizam-se as metodologias ágeis, sendo estas aplicadas, então, em projetos em que há muitas mudanças, em que os requisitos são passíveis de alterações, onde refazer partes do código não é uma atividade que apresenta alto custo, as equipes são pequenas, as datas de entrega do software são curtas e o desenvolvimento rápido é fundamental, não pode haver requisitos estáticos (Soares, 2004, p. 01).

Sendo o Scrum um destes frameworks ágeis, metodologias desse tipo possuem, dentre diversas características, a funcionalidade de serem dinâmicas, isto é, permitem um trabalho mais eficiente perante alterações durante toda a execução do projeto. Devido a esse fato, as startups, empresas jovens com construção contínua dos projetos desenvolvidos, vinculada ao desenvolvimento de ideias inovadoras, optam pela sua utilização devido à convergência de ideias entre as partes (Signori, Martins, Silva, Kalil, \& Capelari, 2014).

Assim, as empresas que possuem foco na eliminação de desperdícios e otimização dos recursos por meio das metodologias ágeis são denominadas Lean Startups e são consideradas ainda mais desafiadoras que as tradicionais devido à inovação contínua dos processos (Oliveira et al., 2020; Silva, Calado, Silva, \& Nascimento, 2013). Diante do exposto, surge uma questão a ser respondida: como a utilização do Scrum impacta a produtividade de uma startup?

Dessa maneira, o presente trabalho tem como objetivo realizar um estudo quanto à aplicação da metodologia ágil Scrum em uma startup de tecnologia no interior de Minas Gerais. O intuito foi verificar o impacto desse framework e como este influencia na produtividade e nos resultados obtidos pelos colaboradores, relacionando, então, o modo de trabalho com as entregas geradas.

Assim, há o propósito de gerar uma avaliação quantitativa e qualitativa dos membros quanto à metodologia; determinar os principais benefícios gerados dentro da organização; identificar as maiores dificuldades enfrentadas desde a sua implantação; avaliar o impacto dessa metodologia na cultura da organização; e, por fim, sugerir melhorias que possam elevar os resultados da empresa.

$\mathrm{O}$ trabalho encontra-se estruturado em seções. Enquanto que a primeira apresenta uma breve introdução sobre o assunto abordado, as outras descrevem todo o trabalho realizado, dividido em uma revisão bibliográfica dos temas abordados, a metodologia utilizada e uma análise dos resultados obtidos, e apresentam as considerações finais com as conclusões geradas.

\section{Metodologia}

Com a problemática definida, realiza-se o trabalho proposto dentro da organização em diversas etapas, sendo a 
primeira a revisão bibliográfica dos principais autores sobre o assunto mencionado.

\subsection{Referencial Teórico}

Gerenciar um projeto é essencial para que os objetivos pré-estabelecidos sejam alcançados com êxito. Isso promove um aprimoramento constante das técnicas de gestão, visto que a competitividade entre as organizações aumentou exponencialmente, e faz com que as empresas busquem formas de manterem bons resultados constantemente. Assim, itens como redução de custos e melhorias dos produtos oferecidos são definidos como essenciais nesse desafio (Padilha, Costa, Contador, \& Marins, 2004).

Baseado nisso, surgiu o conceito do gerenciamento tradicional de projetos que é definido por Vargas (2005, p. 07) como "[...] um conjunto de ferramentas gerenciais que permitem que a empresa desenvolva um conjunto de habilidades [...] destinadas ao controle de eventos não repetitivos, únicos e complexos, dentro de um cenário de tempo, custo e qualidade determinados".

Antes da década de 50, segundo Reis (2004), os projetos eram controlados por técnicas informais, até que Henry Gantt deu início à gestão de projetos. Foram desenvolvidas ações que se difundiram até promoverem a fundação do Project Management Institute (PMI), uma das principais referências no assunto. Essa associação se dedica ao desenvolvimento e capacitação de profissionais que optam pelo trabalho nesta área, sendo que a principal contribuição é o Project Management Body of Knowledge (PMBOK) que compila ações para serem aplicadas e promover bons resultados na execução dos projetos (Lago \& Mingossi, 2007).

Entretanto, em diversas situações, as metodologias clássicas, por terem características como resistência a mudança e foco no planejamento a longo prazo, podem não ser amplamente vantajosas para um determinado projeto, como em desenvolvimento de software (Joaquim, 2011). Dessa forma, como afirma Souza (2014), surgiram iniciativas para encontrar maneiras eficientes para potencializar tais ações, o que deu origem ao Gerenciamento Ágil de Projetos (GAP).

Joaquim (2011, p. 08) define o GAP como "[...] um conjunto de princípios, valores e práticas que auxiliam a equipe de projetos a entregar produtos ou serviços de valor em um ambiente de projetos desafiador". Assim, metodologias como Scrum e Extreme Programming (XP) são caracterizados como incrementais, com entregas temporais e que apresentam grande participação dos clientes durante todo o processo de concepção do projeto (Xavier, 2017). Com esse desenvolvimento em ciclos, há uma abordagem mais flexível e que responde de maneira assertiva as frequentes mudanças e alterações de prioridades dos clientes.

Com a difusão desse movimento ao longo do tempo e a consequente criação de diversas metodologias, em 2001, nos Estados Unidos, dezessete especialistas, que defendiam o planejamento dos processos de maneira moderada, ou seja, desde que se reconheça os limites da previsibilidade, se reuniram (Jesus, 2016). No encontro, estabeleceram princípios em comum que formalizaram a criação do Manifesto Ágil, pautado por quatro valores que priorizavam indivíduos e interações, software em funcionamento, colaboração com o cliente e resposta a mudanças (Eloi, 2016; Sganderla, Lacerda, Ribeiro, \& Silveira, 2016; Soares, 2004; https://agilemanifesto.org/iso/ptbr/manifesto.html).

Assim, muitas empresas estão tentando tornar suas equipes ágeis, pois há benefícios como rapidez, eficiência, qualidade e maior atendimento aos requisitos impostos pelos stakeholders (Souza, 2014). Dentre esse nicho de empresas, estão as startups que são organizações criadas em torno de um modelo de negócio que possui repetibilidade e escalabilidade, com ideias diversificadas que ocasionam incertezas quanto à prosperidade, sendo o GAP uma forma apropriada para gerenciar todo

o trabalho (https://www.sebrae.com.br/sites/PortalSebrae/artigos/o-que-e-uma-startup,6979b2a178c83410VgnVCM10000 03b74010aRCRD).

Dessa forma, a aplicação de metodologias ágeis, como o Scrum, em Lean Startup pode gerar vantagens além das já 
mencionadas. Como afirma Lima (2017), há um maior controle organizacional devido às averiguações constantes, maiores oportunidades para elaboração de estratégias, um direcionamento assertivo de recursos e, ainda, solução de problemas mais frequentes.

Baseado nessa premissa, o Scrum permite uma atuação em áreas diversas, como o setor de vendas, pois, apesar de não ser em desenvolvimento de software, formulação inicial do framework, a aplicação pode proporcionar diversas vantagens quando for adaptada e executada com êxito (Camargo et al., 2019; Leonel, Amorim, Sousa, \& Mendes, 2018; Silva, 2011). Tal premissa é válida inclusive na organização quanto à execução de planos de ação de métricas e indicadores chaves da empresa, como Key Perfomance Indicators (KPI's) e Objective Key Results (OKR's).

O Scrum surgiu quando cientistas publicaram um estudo com a proposta de um novo modelo de trabalho em que "[...] as fases possuíam forte intersecção e todo o processo era desenvolvido por times multifuncionais [...]" como o esporte coletivo inglês rugby (Silva \& Lovato, 2016). Nessa atividade esportiva, a bola atravessa o campo de acordo com o avanço dos jogadores, como uma unidade, sendo essa a origem do Scrum, cujo esquema de trabalho, baseado nos três pilares da metodologia ágil - transparência, inspeção e adaptação - é visto na Figura 1 (Loriggio, Farias, \& Mustaro, 2013).

Figura 1. Ciclo de vida do Scrum.

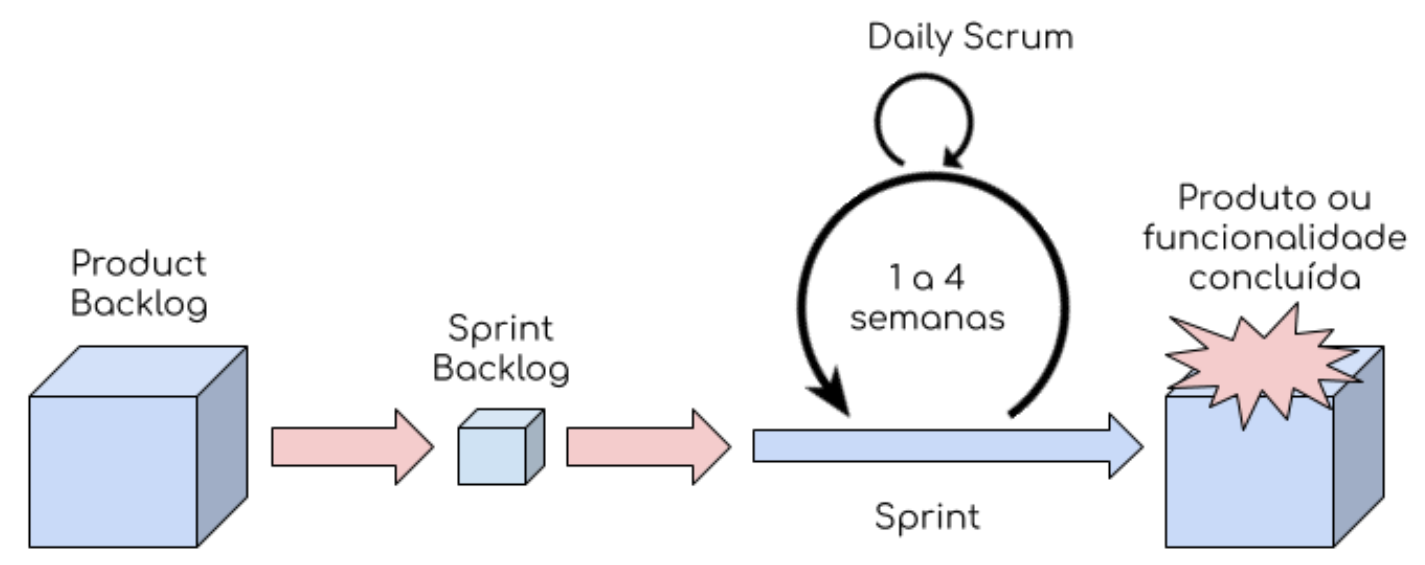

Fonte: Adaptado de Balle, A. R. (2011). Analise de metodologias ágeis: conceitos, aplicações e relatos sobre XP e Scrum (Trabalho de conclusão de curso). Universidade Federal do Rio Grande do Sul, Porto Alegre, RS, Brasil. http://www.lume.ufrgs.br/handle/10183/31028

O processo se repete em forma de Sprints, intervalos de tempo pré-estabelecidos, sendo que se inicia com uma lista priorizada com todas as ações a serem executadas presentes no Backlog (Fadel \& Silveira, 2010). Durante uma reunião intitulada Planning, seleciona-se e estima-se por meio do Planning Poker as atividades que irão serem realizadas na Sprint (Silveira, 2012), iniciando a próxima etapa em que todo o time executa o máximo de tarefas propostas que conseguirem.

Durante a Sprint, diariamente, a equipe se reúne no Daily Scrum "[...] para averiguar o acompanhamento do progresso, usando para isto o Burndown Chart, que é um gráfico usado para acompanhamento [...]" (E. C. Silva \& Lovato, 2016, p. 03), com o propósito de alinhar todo o trabalho e promover discussões em relação as atividades. Já ao final, são revistas as entregas que foram geradas e discutidos os erros e acertos com o intuito de transformar as experiências em aprendizado para promover uma melhoria contínua, repetindo todo o ciclo (Andrade, Oliveira, Barbosa, \& Silveira, 2012).

Para que a metodologia funcione, existem três papéis principais dentro desse mecanismo de trabalho. De acordo com Fadel e Silveira (2010) são eles: Time Scrum, equipe de projeto que realiza as ações; Scrum Master, referência na metodologia; e Product Owner, responsável pelo gerenciamento do projeto. Com essa divisão em etapas e funções, é possível obter diversos benefícios e vantagens com a aplicação da metodologia Scrum. Aspectos como autonomia para os colaboradores e aumento na comunicação entre os indivíduos são valorizados e, assim, há um maior engajamento nos participantes dos projetos que irão 
resultar, consequentemente, em melhores resultados para a empresa (Sutherland, 2014).

Dessa maneira, se realiza uma classificação da presente pesquisa em diferentes itens, sendo eles:

- Objetivos: explicativa pois busca-se identificar os fatores que ocasionam um determinado fenômeno em análise (Gil, 2002);

- Natureza: básica visto que há o intuito de gerar novos conhecimentos, sem realizar uma aplicação prática prevista (Gerhardt \& Silveira, 2009);

- Abordagem: quanti-qualitativa já que se mistura dados representados numericamente com dinâmicas sociais (Fonseca, 2002)

- Procedimentos: estudo de caso pois esta é uma investigação empírica de um fenômeno dentro de um determinado contexto que busca conhecer todos os aspectos envolvidos (Martins, Mello, \& Turrioni, 2014).

Dessa forma, o tipo de pesquisa é resumido no Quadro 1.

Quadro 1 - Classificações da presente pesquisa.

\begin{tabular}{|c|c|c|c|}
\hline Objetivo & Natureza & Abordagem & Método \\
\hline Explicativa & Básica & Quanti-qualitativa & Estudo de caso \\
\hline
\end{tabular}

Fonte: Autores (2020).

\subsection{Método de trabalho}

Após a classificação da pesquisa e a delimitação das áreas que se pretende abranger, o trabalho é executado e os procedimentos são empregados na execução de todo o projeto.

\subsubsection{Instrumento}

Para que isso ocorra com êxito, são utilizadas as etapas mencionadas por Yin (2001/1984) para um estudo de caso, vistas na Figura 2.

O autor afirma que a primeira etapa é a de definição e planejamento de todo o projeto de pesquisa, isto é, a preparação de tudo que será trabalhado ao longo do estudo. Baseado nisso, então, definiu-se qual o problema será explorado pelo presente trabalho. Determina-se que será estudada a aplicação do Scrum, uma metodologia ágil, e a sua relação com a produtividade da empresa envolvendo aspectos como efetividade, qualidade e produtividade, tanto na visão dos colaboradores, quanto em relação aos resultados que são alcançados. Além disso, definiu-se também que o local de estudo será uma startup tecnológica presente no estado de Minas Gerais. 
Figura 2. Etapas de um estudo de caso.

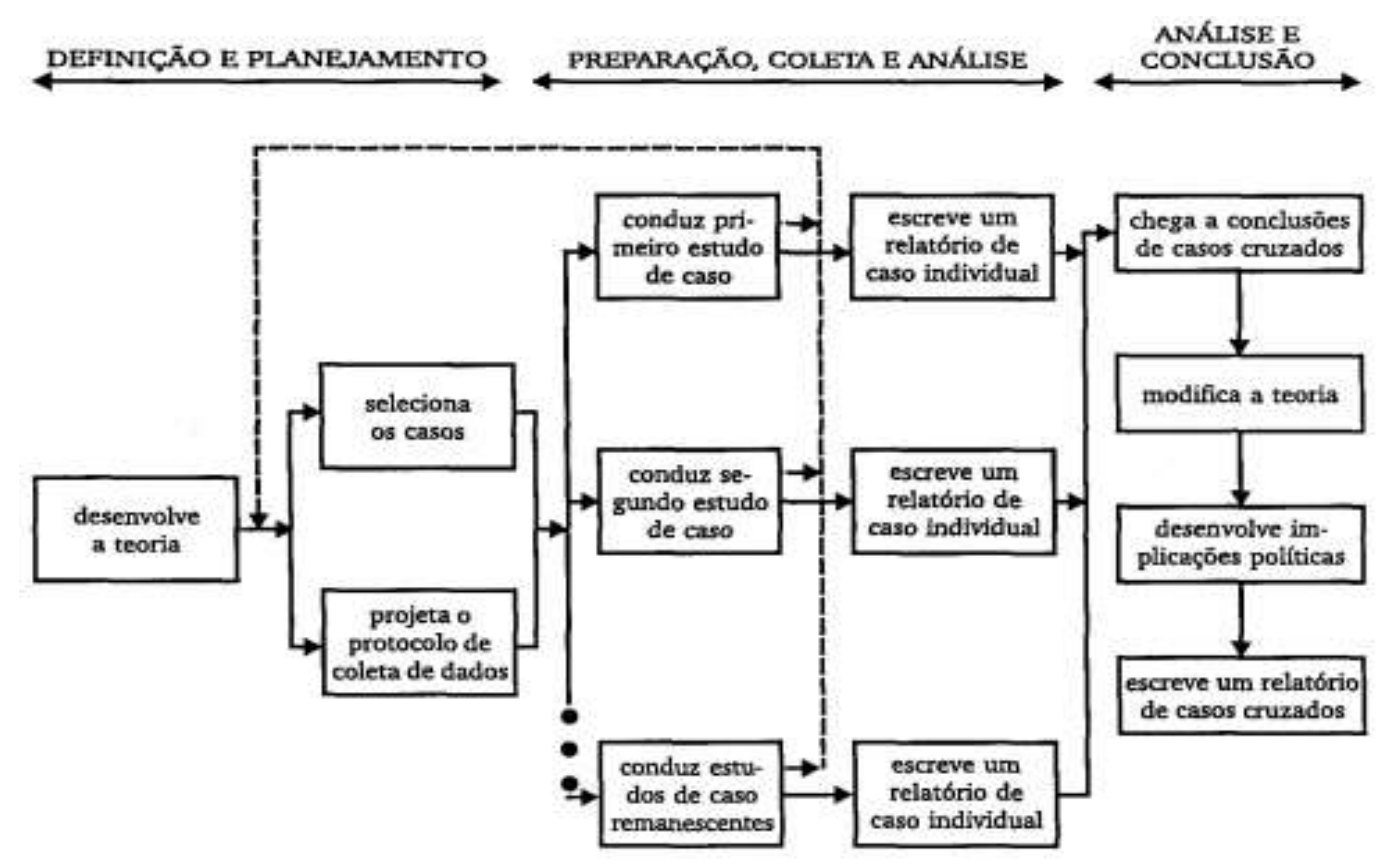

Fonte: Yin. (2001).

Em seguida, realizou-se uma revisão bibliográfica dos principais assuntos relacionados ao tema principal do trabalho, apresentado na seção anterior. Isso se dá com o intuito de obter conhecimentos quanto ao tema e ter embasamento para todas as posteriores ações e análises, elevando, portanto, a qualidade, visto que há o suporte de obras de diversos autores.

Com a formulação de possíveis proposições de estudo para garantir uma boa condução da pesquisa, finalizou-se a primeira etapa mencionada por Yin (2001/1984). Depois disso, portanto, é o momento da preparação, coleta e análise de dados, sendo que tal ação se inicia com a elaboração de uma entrevista a ser feita de maneira semiestruturada com os colaboradores da organização, com o intuito de obter o máximo de informações possíveis que auxiliem na resolução da problemática mencionada.

Finalmente, após a coleta dos dados, haverá uma análise e conclusão dos dados obtidos, sendo a terceira e última etapa, segundo Yin (2001/1984), em que serão obtidas as informações buscadas inicialmente. O compilado das informações será apresentado nos tópicos posteriores do presente trabalho.

\subsubsection{Instrumento $\mathrm{N}^{\circ} 2$}

A empresa analisada pertence à um grupo que também atua em outras frentes, como padaria e hotel. Ela foi fundada em novembro de 2015 e atua no setor de postos de combustíveis com o objetivo de proporcionar melhores resultados para as organizações desse ramo.

Esse trabalho é feito por meio do gerenciamento de um programa de fidelidade próprio, em que o objetivo consiste em aproximar o revendedor de combustível com os seus clientes, aumentando, consequentemente, aspectos como qualidade e receita. Além disso, também há o fornecimento de ferramentas de controle de metas dos frentistas e um auxílio ao gerenciamento completo do posto, permitindo, portanto, que o gestor consiga elevar ao máximo os seus resultados.

Com atuação em mais de setecentos pontos dispersos por vinte e seis estados brasileiros, a equipe realiza todo o trabalho em uma única sede, onde controla os softwares de maneira on-line e remota. Dentro do polo, atuam setenta e um funcionários divididos em onze times, Marketing, Hunters, Closers, Financeiro, Onboarding, Customer Success, Suporte, 
Gente, Operação, Produto e Desenvolvimento, sendo que a estrutura organizacional está disposta na Figura 3.

Figura 3. Estrutura organizacional da empresa em análise.

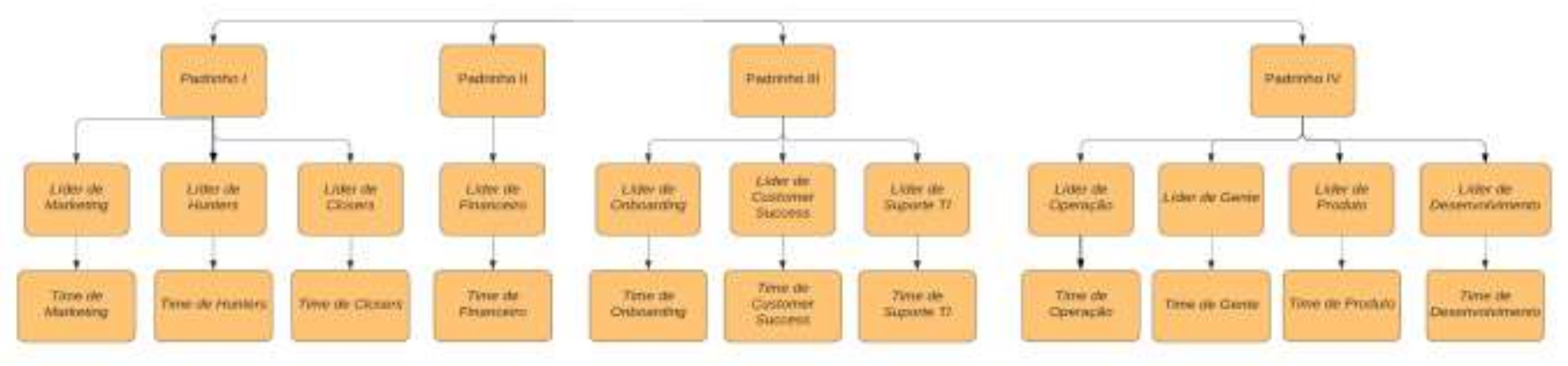

Fonte: Autores (2020).

Como é possível visualizar na Figura 3, há a presença de quatro gestores, denominados padrinhos, sendo que cada um é responsável por uma determinada quantidade de áreas. Além disso, cada um dos times (setores), possui um líder que gerencia o trabalho feito pelos seus respectivos colaboradores. De toda a equipe da empresa (71 colaboradores), 68,5\% são efetivados, 28,76\% são estagiários e 2,74\% são jovem-aprendiz. Essa heterogeneidade torna a empresa dinâmica e, aliado a uma cultura autônoma, ágil e descomplicada, como afirma alguns de seus valores, há um crescimento exponencial ao longo do tempo.

Essa expansão se tornou tão grande que o método de gestão utilizado não estava sendo mais eficiente como se esperava. A primeira técnica utilizada, Getting Things Done, que consiste em listar todas as pendências a serem sanadas, agrupar em esferas, e realizá-las continuamente, se tornou inviável, já que o número de membros aumentou e as entregas e o acompanhamento das tarefas eram feitos de maneira individual e informal.

Assim, com a contratação de novas pessoas e um conhecimento básico em Scrum, um dos diretores optou por delegar uma pessoa para que houvesse a implantação da metodologia dentro da empresa em 2018. Dessa maneira, apesar de muitos obstáculos como resistência e troca de ferramenta (sendo o Asana o instrumento de trabalho atual), a metodologia da gestão de projetos foi aprimorada desde o seu início nos times de Customer Success e Marketing. Estes começaram com a inserção de rotina dentro da Sprint e, ao longo do tempo, evoluíram para atividades de melhoria contínua, sendo utilizada atualmente em todas as áreas.

Facilitado pelo time denominado Operação, composto por seis pessoas (2 efetivados e 4 estagiários), a metodologia tende a promover alguns dos benefícios citados e, para que funcione com êxito, necessita de aprimoramento constante para que os preceitos do Scrum sejam empregados com sucesso. Assim, tende a se adaptar frente às mudanças que ocorrem dentro da empresa, como a entrada de novos membros e alterações nos processos.

Para isso, portanto, realizou-se uma entrevista semiestruturada com uma amostra de colaboradores da startup, permitindo uma confiabilidade de 90\%, em que se foi possível obter a percepção destes quanto à metodologia. Nesse encontro, foram questionados alguns pontos como conhecimento da metodologia, impacto no trabalho, influência da cultura da empresa, auxílio dos gestores, execução dos procedimentos pré-estabelecidos, alinhamento entre o time, influência em metas e resultados, resolução dos impedimentos relatados e promoção da melhoria contínua, sendo os resultados apresentados na seção seguinte.

\section{Resultados e Discussão}

Como abordado, a entrevista foi realizada de maneira semiestruturada com 57 colaboradores da startup em um 
período de duas semanas, apoiada em um questionário apresentado no Quadro 2 do presente documento, sendo que fora utilizado questões abertas para que aspectos ocultos pudessem ser descobertos por meio das respostas e questionados durante as entrevistas. Dessa maneira, tornou-se possível obter algumas informações quanto à influência da metodologia ágil na startup em análise. Os resultados serão apresentados no decorrer deste tópico.

Quadro 2. Questionário para entrevista.

\begin{tabular}{|c|c|}
\hline \multicolumn{2}{|c|}{ Informações pessoais } \\
\hline 1. & Qual o seu nome? \\
\hline 2. & Qual o seu time? \\
\hline 3. & Há quanto tempo você trabalha na startup? \\
\hline 4. & Qual a sua formação profissional? \\
\hline \multicolumn{2}{|c|}{ Percepção da metodologia } \\
\hline 5. & Qual o seu papel dentro da metodologia? \\
\hline 6. & Você conhecia a metodologia Scrum antes de fazer parte do startup? \\
\hline 7. & De 1 a 10, o quanto você compreende por completo os procedimentos da metodologia? \\
\hline 8. & De 1 a 10, o quanto você acredita que a metodologia auxilia na organização do seu trabalho? \\
\hline 9. & Comparando com as suas experiências anteriores, você conseguiria organizar o seu trabalho sem o Scrum? \\
\hline 10. & De que maneira a metodologia Scrum te auxilia? \\
\hline 11. & Na sua opinião, a cultura da empresa auxilia na execução aprimorada da metodologia? \\
\hline 12. & De que forma os seus gestores (líderes ou padrinhos) auxiliam na execução da metodologia? \\
\hline 13. & Dos rituais realizados, qual é o mais difícil de ser executado? Por quê? \\
\hline 14. & E o mais fácil? Por quê? \\
\hline 15. & E qual dos rituais promove um maior alinhamento entre o time? Por quê? \\
\hline 16. & Você acha que o Scrum propicia o atingimento de metas como as OKR's? Se sim, de que forma? \\
\hline 17. & Você tem o costume de relatar os impedimentos que ocorrem? \\
\hline 18. & Você possui o auxílio necessário do Scrum Master para resolver os impedimentos que são relatados? \\
\hline 19. & Com que frequência você adiciona tarefas no Backlog do seu time? \\
\hline 20. & Você acredita que entrega as suas tarefas com máxima qualidade? \\
\hline 21. & A melhoria contínua é promovida por meio de atividades realizadas nos Sprints? Justifique. \\
\hline 22. & Quais as maiores dificuldades que você encontra na execução da metodologia? \\
\hline 23. & Para encerrar, quais são as suas considerações sobre a metodologia Scrum? \\
\hline
\end{tabular}

Primeiramente, os colaboradores foram questionados quanto às informações básicas como o setor em que trabalham, tempo de vínculo com a empresa e a formação profissional. Tais indagações possuem o intuito de relacionar estes aspectos com a percepção individual dos membros em relação à execução do Scrum. Além disso, também foi questionado a função que exercem dentro do Scrum para se entender os parâmetros do colaborador no momento em que respondem a pesquisa, sendo 77,8\% dos entrevistados componentes do Time Scrum, 19,2\% Product Owner e 3\% da equipe Scrum Master.

Dessa forma, $60 \%$ de todos entrevistados afirmaram que não conheciam a metodologia antes de fazer parte da equipe da startup e que estavam trabalhando com o framework pela primeira vez. Por esse motivo, já ocorreram alguns treinamentos internos com o objetivo de explicar o funcionamento da metodologia e, à medida em que novas pessoas entram na empresa, essa capacitação é renovada.

Já em uma análise de acordo com a função quanto aos conhecimentos sobre os procedimentos da metodologia, visto 
na Figura 4, é possível analisar que os Scrum Masters da organização - estagiários, com menos de três meses nas suas funções atuais, graduandos nos cursos de Engenharia de Produção e Engenharia de Materiais - afirmam não conhecerem por completo os procedimentos executados. Isso é um problema já que estes devem ser a principal referência da metodologia dentro da organização, sendo necessário um trabalho interno para que essa situação seja aprimorada.

Já em relação aos Product Owners, todos afirmaram entender mais de $70 \%$ dos procedimentos, sendo que $27,3 \%$ atribuíram nota máxima para os seus conhecimentos sobre o Scrum. Dentro dessa categoria, de todos os profissionais entrevistados, apenas $27,3 \%$ não possuem mais de dois anos de tempo de serviço dentro da startup, sendo que isso significa que todos os outros executaram os seus trabalhos na empresa sem a utilização do Scrum. Ainda assim, 72,3\% afirmaram que não conseguiriam organizar as suas atividades de maneira tão efetiva como é atualmente sem o auxílio do Scrum.

Figura 4. Conhecimentos dos procedimentos.

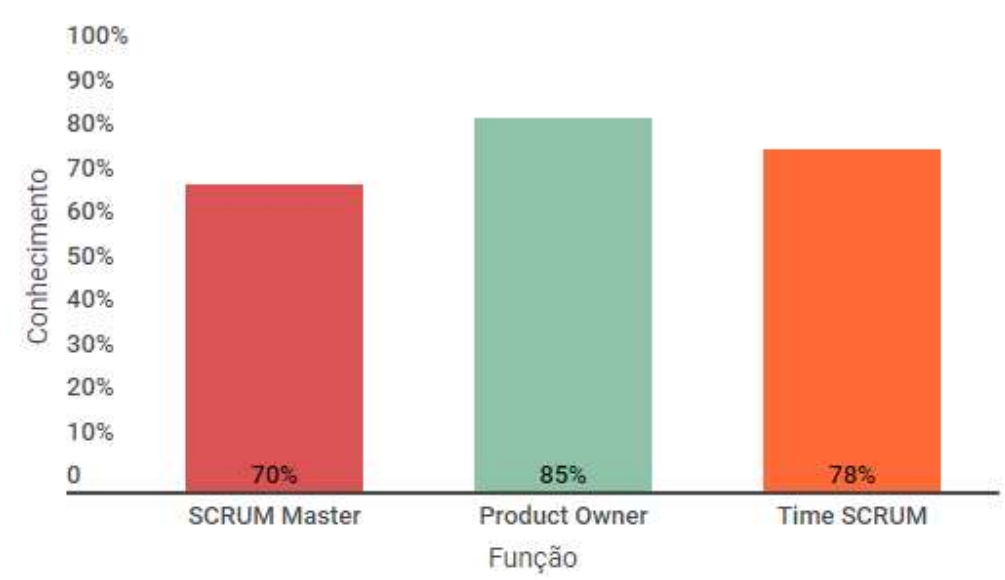

Fonte: Autores (2020).

Por fim, quando se questiona o Time Scrum sobre o seu nível de habilidade na execução da metodologia, tem-se os dados exibidos na Figura 5. Como é possível concluir, apenas 11,4\% dos colaboradores conhecem pouco dos rituais que são realizados (até 60\%). Apesar do número baixo, apenas 9,1\% afirmam se considerar experts na execução do Scrum (100\%). Logo, torna-se necessário a ocorrência de outros treinamentos e capacitações que possam compartilhar conhecimentos relacionados ao framework e promover, portanto, uma maior gestão do conhecimento entre todos os colaboradores.

Figura 5. Compreensão da metodologia pelo Time Scrum.

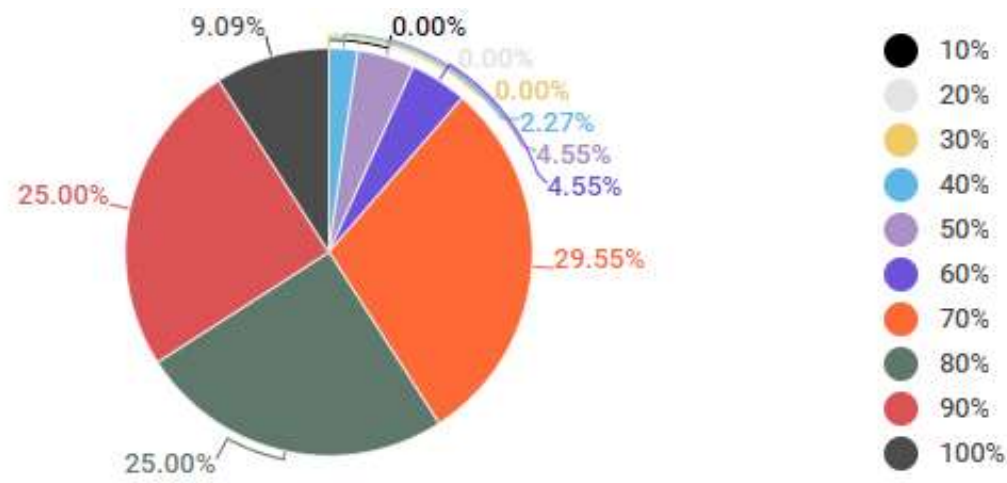

Fonte: Autores (2020). 
Dentre os benefícios mencionados pelos entrevistados, de maneira geral, é possível destacar itens como: o auxílio no planejamento, adaptação constante, cooperação, organização das tarefas e priorização do que irá gerar mais valor para os envolvidos. Além disso, grande parte das pessoas destacaram também a gestão a vista, sendo uma técnica em que todo o controle do que está sendo feito é exposto de maneira fácil para todos. Segundo alguns dos colaboradores, esse método de administração é um grande benefício do framework e é primordial para que os benefícios citados acima possam ser gerados com êxito.

Além disso, também houve menção quanto a dimensão de tempo como um aspecto positivo do Scrum. Isto é, como há a execução de ciclos quinzenais, as atividades realizadas em uma Sprint, em diversas ocasiões, são parte de projetos maiores que se subdividem em pequenas tarefas. Dessa forma, há uma quebra de planos de longo prazo em pequenos espaços de tempo, ou seja, divide-se projetos em frações menores, o que permite a progressão do mesmo de maneira satisfatória.

Quando indagados quanto à cultura da startup e a influência desta na metodologia, 86,9\% dos entrevistados acreditam que a cultura auxilia em uma execução aprimorada do Scrum, porém, para alguns, ainda há fatores a serem trabalhados. Foi citado, por exemplo, a falta de envolvimento concreto dos diretores com os preceitos da metodologia e a utilização de maneira assertiva. Torna-se necessário, portanto, ações para que esse problema seja sanado, já que os padrinhos são as figuras representativas máximas da empresa e adquirem, então, a responsabilidade de difundir ideias e informações com excelência.

Baseado nessa premissa, foi questionado qual é o auxílio dos gestores, tanto os diretores quanto os líderes, durante a execução do Scrum. Analisando as respostas obtidas, é possível verificar que não há uma influência direta dos diretores no trabalho feito dentro da metodologia. Em alguns times, a autonomia é maior e o padrinho apenas sugere ideias para adentrarem o Backlog e questionam, ocasionalmente, o andamento das tarefas sugeridas. Nesses casos, todos relataram essa liberdade como um ponto positivo já que demonstra confiança nos colaboradores, sendo que $75,4 \%$ destes, afirmam entregar as suas tarefas com máxima qualidade.

Em outros times, também há a presença da situação relatada, porém, em contrapartida, os ciclos do Scrum não são respeitados e nem priorizados como se espera pelos diretores. Dessa forma, o padrinho do time adiciona tarefas não planejadas, fora do Planning, durante a Sprint, o que atrapalha o trabalho do setor, visto que danifica o seu planejamento.

Além disso, como o Scrum objetiva a melhoria contínua, o trabalho é visto como algo complementar pelo diretor e, consequentemente, por todo o Time Scrum. Isso prejudica a priorização das tarefas selecionadas para a Sprint no cotidiano dos colaboradores, já que estes são cobrados pelos resultados gerados em relação à rotina e não à melhoria contínua. Torna-se válido, novamente, a realização de uma capacitação com todos os envolvidos com o objetivo de mostrar a importância da melhoria, dentro dos processos executados e o impacto direto gerado pelas ações feitas nos resultados do time.

Já em relação à influência do Product Owner dentro da metodologia, grande parte dos entrevistados afirmaram que o trabalho é mais próximo. Assim, os líderes ajudam na elaboração das tarefas, refinam as ideias inseridas pelos membros no Backlog, instruem os colaboradores a realizarem as atividades e, ainda, verificam o andamento das tarefas com o objetivo de acelerar as entregas do time. Dessa forma, como há um contato mais direto e pessoal, existe uma comunicação efetiva entre as partes, de maneira constante e satisfatória na maioria das vezes.

Essa comunicação é realizada em diversos momentos dentro dos procedimentos da metodologia. Devido a isso, Planning, Daily, Review ou Retrospective promovem um maior alinhamento de ideias entre os membros, sendo o resultado apresentado na Figura 6. É possível concluir que 68,4\% dos colaboradores acreditam que o Planning promove um maior alinhamento de ideias entre os membros, pois gera discussão entre todos.

O alinhamento é fundamental para que o Scrum auxilie no alcance dos objetivos pré-estabelecidos, como as OKR's. Segundo os membros, quando a metodologia é utilizada com êxito, as possibilidades de se atingir as metas são maiores, sendo feitas por meio da inserção de planos de ação pré-estabelecidos para atingimento das metas dentro das Sprints. 
Figura 6. Ritual que promove maior alinhamento de ideias.

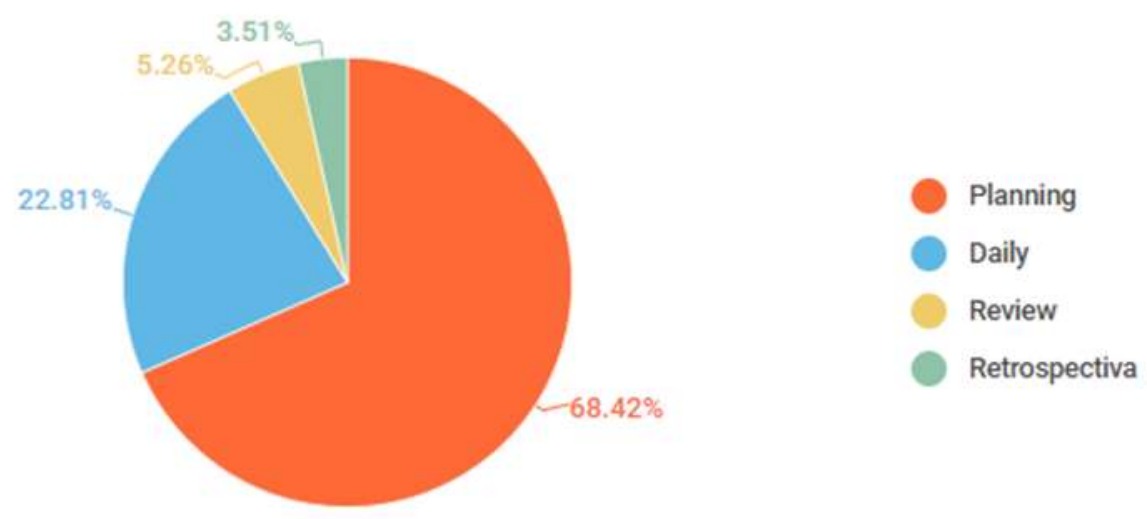

Fonte: Autores (2020).

Com o intuito de verificar o andamento dessas e de outras tarefas e solucionar possíveis impedimentos, o Scrum Master realiza Dailys nos times. Entretanto, 17,5\% dos entrevistados, não relatam os empecilhos que ocorrem, por motivos diversos, como sensação de independência e autonomia para resolverem de forma própria. Assim, torna-se necessário salientar a importância de mencionar os problemas que ocorrem por meio de estudos temporais, contendo impedimentos que foram sanados, como já aconteceu anteriormente na empresa.

Os colaboradores foram questionados também sobre as maiores dificuldades que encontram durante a execução da metodologia na questão 22. Dentre as respostas obtidas, fora mencionado adversidades nas tarefas que envolvem outros times pois, em algumas situações, as tarefas de áreas que dependem de uma ação de terceiros, tendem a não serem priorizadas no cotidiano. Isso atrasa a finalização das mesmas, sendo que os diretores estão incluídos em tal situação quando é necessário a tomada de decisão destes.

De maneira semelhante, porém de forma oposta, quando uma tarefa é realizada por um time demandada por outro, como uma solicitação do Comercial para o Marketing, há a ocorrência de retrabalho, visto que informações necessárias para a sua execução tendem a não estarem dispostas de maneira completa. Assim, o time executor adquire a incumbência de procurar o responsável pela ideia, tendo que retardar o início do trabalho.

Uma solução para esse problema é a obrigação da utilização de um formulário, em que para que a tarefa seja realizada, o criador deve preencher todas as informações necessárias, elevando o nível de rigidez e burocracia entre os times item que contraria os princípios da metodologia ágil. Isto se torna necessário, já que divergências estão sendo ocasionadas com grande frequência dentro da empresa.

Muitas pessoas também mencionaram possuir dificuldades em executar alguns dos procedimentos do Scrum como:

- Planning Poker, já que é necessário mensurar o esforço de uma tarefa com base em sua explicação;

- Priorização de tarefas, já que há muitos interesses envolvidos no time;

- Quebra das tarefas, de maneira que se consiga obter um Gráfico de Burndown satisfatório;

- Criação de um Backlog que consiga gerar um bom planejamento do que se espera para o time na próxima quinzena, frente a todas as demandas que existem a médio e a longo prazo.

Ademais, outras dificuldades mencionadas foram em relação à um aspecto principal que prejudica quase todos os times atualmente: gestão do tempo. Tal item não é trabalhado dentro da empresa com frequência e, apesar de utilizarem uma agenda on-line compartilhada que possibilita a marcação de eventos e anotações, as tarefas da Sprint não são contempladas nessa gestão com eficiência. Assim, acabam sendo realizadas em intervalos entre as atividades da rotina, caso essas não 
estejam contempladas em forma de desafio dentro da Sprint. Dessa maneira, salientar a importância de se realizar essa gestão com sucesso pode agregar impactos positivos dentro da empresa em diferentes aspectos.

É possível, portanto, sintetizar os principais benefícios encontrados e dificuldades a serem sanadas pela empresa no Quadro 3 a seguir.

Quadro 3. Principais benefícios e dificuldades.

\begin{tabular}{|c|c|}
\hline Benefícios & Dificuldades \\
\hline Adaptação & Comunicação entre times \\
\hline Ciclos curtos & Falta de envolvimento dos diretores \\
\hline Cooperação & Gestão do tempo \\
\hline Gestão à vista & Montagem de Backlog \\
\hline Organização & Propagação do trabalho como extra \\
\hline Planejamento & \\
\hline Priorização & \\
\hline
\end{tabular}

Fonte: Autores (2020).

Diante de todo o exposto, portanto, por meio da geração de uma análise qualitativa e quantitativa da metodologia, identificação dos principais benefícios e dificuldades vivenciadas e o impacto deste framework na empresa, é possível concluir que o Scrum dentro da startup tem evoluído e aprimorado os seus procedimentos com constância. Um exemplo é a inserção de uma reunião Pré-Planning, procedimento não incluso na metodologia, com o intuito de auxiliar o time a montar o seu Backlog com ainda mais êxito. Dessa maneira, muitos colaboradores relataram, inclusive, que já utilizam a metodologia em projetos pessoais devido aos diversos benefícios gerados pelo Scrum.

\section{Considerações Finais}

De maneira geral, é possível afirmar que, dentro da startup, o Scrum funciona de maneira efetiva para todos os membros em diferentes aspectos, como abordado nos resultados da pesquisa realizada. Cada colaborador possui os seus prós e contras em relação à metodologia, sendo que a sua utilização tem se aprimorado de maneira constante ao longo do tempo.

Dessa forma, enquanto que no início havia problemas de implementação, como resistência à mudança, atualmente os problemas são outros. Como há uma bonificação por time baseada no resultado da Sprint, torna-se necessário, estudos em cima das respostas entregues para validar a qualidade das tarefas realizadas. Assim, como foi possível concluir também, o time responsável pela execução do Scrum criou um indicador baseado em alguns pilares - progressão entre os ciclos, taxa de atividades não-planejadas e \% de Backlog prévio - que objetivam metrificar a qualidade da Sprint. As dificuldades atuais são, novamente, a mensuração de qualidade dessas tarefas e o impacto positivo gerando.

Por meio dessa pesquisa, ainda, pode-se concluir que, de maneira geral, os membros gostam da metodologia executada, veem benefícios na sua utilização e baseiam os seus trabalhos em cima do Scrum. Muitos profissionais destacaram também que as melhorias realizadas dentro do time só são possíveis por causa da metodologia, visto que permite o trabalho de maneira mais eficaz e profunda. 
Entretanto, ainda há dificuldades a serem sanadas para que haja uma adaptação para a realidade vivenciada, de maneira que consiga aprimorar a relação rotina e melhoria contínua e, assim, possibilitar que os membros consigam aperfeiçoar a execução do Scrum e elevar ainda mais os seus resultados. Ações como reuniões, aulas, treinamentos, capacitações, palestras e dinâmicas que promovam o compartilhamento do conhecimento para que todos possam aprender ao máximo da metodologia são necessárias. Isso poderá garantir, também, o trabalho em cima da cultura ágil da empresa, visto que essa é fundamental para que a metodologia se difunda continuamente com sucesso.

É possível concluir, por fim, que o tempo de prestação de serviço do colaborador dentro da startup e a sua formação profissional não é um fator diferencial para a obtenção de conhecimentos no Scrum. Enquanto que o primeiro fator gera maior tempo de prática e o segundo indica o grau de instrução do colaborador, o que valida a execução da metodologia em cada um, é o grau de esforço de trabalho. Isto é, quanto mais alto for fatores como engajamento e priorização, consequentemente maiores serão a organização, o planejamento e a rapidez nas tarefas e, assim, por conseguinte, eleva-se a produtividade e a qualidade de toda a empresa.

Para trabalhos futuros, sugere-se uma ampliação de estudo da cultura ágil da empresa em análise para que outros aspectos também possam ser absorvidos e, além disso, realizar comparações científicas com pesquisas de objetivo semelhante para que diferentes conclusões e aspectos possam ser obtidos e observados em prol da melhoria contínua dos processos. De forma geral, sugere-se ainda estudos relacionados a maturidade da gestão ágil das organizações, entendendo o nível gerado pelas práticas aplicadas nas empresas, implicações em resultados e as diversas possibilidades de atuação do framework nos projetos.

\section{Referências}

Andrade, A. J. F., Oliveira, J. C., Barbosa, P. A. M., \& Silveira, F. R. de V. (2012, novembro). Gestão de projeto com Scrum: um estudo de caso. Anais do Encontro Unificado de Computação. Parnaíba, PI, Brasil, 4. https://www.enucomp.com.br/2012/conteudos/artigos/scrum.pdf

Balle, A. R. (2011). Analise de metodologias ágeis: conceitos, aplicações e relatos sobre XP e Scrum (Trabalho de conclusão de curso). Universidade Federal do Rio Grande do Sul. http://www.lume.ufrgs.br/handle/10183/31028

Camargo, K. G. A. et al. (2019). Aplicação do Modelo Squad Health Check em times ágeis de uma instituição financeira. Research, Society and Development, 9(2), 1-17. http://dx.doi.org/10.33448/rsd-v9i2.2212

Eloi, D. S. A. (2016). Um estudo comparativo de metodologias ágeis no desenvolvimento de aplicativos móveis (Trabalho de conclusão de curso). Universidade Federal do Pernambuco, Recife, PE, Brasil. https://www.cin.ufpe.br/ tg/2016-2/dsae.pdf

Fadel, A. C., \& Silveira, H. M. (2010). Metodologias ágeis no contexto de desenvolvimento de software: XP, Scrum e Lean (Trabalho de conclusão de curso). Universidade Estadual de Campinas. http://www.ft.unicamp.br/liag/Gerenciamento/monografias/Lean\%20Agil_v8.pdf

Fonseca, J. J. S. (2002). Metodologia da pesquisa científica [Apostila da Metodologia da pesquisa científica]: Editora da Universidade Estadual do Ceará.

Gerhardt, T. E., \& Silveira, D. T. (Coord.). (2009). Métodos de pesquisa [Apostila do Métodos da Pesquisa]: Editora da Universidade Federal do Rio Grande do Sul.

Gil, A. C. (2002). Como elaborar projetos de pesquisa (4a ed.): Atlas.

Jesus, I. P. S. (2016). Metodologias ágeis para gerenciamento de projetos para startups (Monografia de Especialização). Universidade Federal de Minas Gerais, Belo Horizonte, MG, Brasil. https://repositorio.ufmg.br/bitstream/1843/ESBF-A9EH4J/1/monografia_italo_paolo_final.pdf

Joaquim, G. M. C. (2011). Estudo sobre a aplicação de métodos de gerenciamento ágil de projetos para o desenvolvimento de painéis de média tensão (p. 08) (Trabalho de conclusão de curso). Universidade de São Paulo, São Carlos, SP, Brasil. http://www.tcc.sc.usp.br/tce/disponiveis/18/180500/tce-30032012$100828 /$ ? \&lang=br

Lago, D., \& Mingossi, R. A. (2007). Gerenciamento de projetos segundo as normas preconizadas pelo PMI® - Um estudo de caso. Revista de Ciências Exatas e Tecnologia, 2(2), 38-52. https://doi.org/10.17921/1890-1793.2007v2n2p38-52

Laurindo, F. J. B., Shimizu, T., Carvalho, M. M., \& Rabechini, R., Jr. (2001, agosto). O papel da tecnologia da informação (TI) na estratégia das organizações. Gestão \& Produção, 8(2), 160-179. https://dx.doi.org/10.1590/S0104-530X2001000200005

Leonel, J. P., Amorim, F. A., Sousa, A. P., \& Mendes, D. P. (2018). Aplicação da Metodologia Ágil Scrum no setor de Marketing de uma IES. Revista Científica Semana Acadêmica, 1(24), 01-15. https://semanaacademica.org.br/system/files/artigos/artigo_1_-_revista_semana_academica_1.pdf 
Lima, T. N. (2017). Metodologia de sistemas flexíveis e sua aplicação em projetos de tecnologia da informação em startups (Monografia de Especialização). Instituto Federal de Educação, Ciência e Tecnologia, São Paulo, SP, Brasil. https://spo.ifsp.edu.br/im ages/phocadownload/DOCUMENTOS_MENU_LATERAL_FIXO/POS_GRADUAÇÃO/ESPECIALIZAÇÃO/Gestão_da_Tecnologia_da_Informação_

PRODUCAO/2017/Metodologia_de_Sistemas_Flexíveis_e_sua_Aplicação_em_Projetos_de_Tecnologia_da_Informação_em_Startups.pdf

Loriggio, A. F., Farias, V. M., \& Mustaro, P. N. (2013, março). Aplicações de gamificação e técnicas de motivação à aprendizagem da metodologia ágil Scrum. Anais do International Conference On Engineering And Computer Education, Luanda, Angola, 8. https://doi.org/10.14684/ICECE.8.2013.328-332

Marques, L. J., Jr., \& Plonski, G. A. (2011). Gestão de projetos em empresas no Brasil: abordagem "tamanho único"? Gestão \& Produção, 18(1), 01-12. http://dx.doi.org/10.1590/S0104-530X2011000100001

Martins, H. C., Moura, M. T., \& Mesquita, J. M. C. (2011). Escritórios de Projetos como Resposta Estratégica da Organização: Um Estudo de Caso na Vale. Revista de Gestão e Projetos, 2(2), 26-52. http://dx.doi.org/10.5585/gep.v2i2.33

Martins, R. A., Mello, C. H. P., \& Turrioni, J. B. (2014). Guia para elaboração de monografia e TCC em engenharia de produção: Atlas.

Oliveira et al. (2020). Gerenciamento de leitos na urgência e emergência utilizando o kanban. Research, Society and Development, 9(10), 01-17. http://dx.doi.org/10.33448/rsd-v9i10.8354

Padilha, T. C. C., Costa, A. F. B., Contador, J. L., \& Marins, F. A. S. (2004). Tempo de implantação de sistemas ERP: análise da influência de fatores e aplicação de técnicas de gerenciamento de projetos. Gestão \& Produção, 11(1), 65-74. http://dx.doi.org/10.1590/S0104-530X2004000100006.

Reis, C. A. A. (2011). A importância do escritório de projetos no gerenciamento de projetos: um estudo de caso da MRS Logística S.A (Trabalho de conclusão de curso). Universidade Federal de Juiz de Fora. http://www.ufjf.br/engenhariadeproducao/files/2014/09/2011_3_Caio.pdf

Sganderla, M. A., Lacerda, G., Ribeiro, V. G., \& Silveira, S. R. (2016). Aprimorando a gerência e o desenvolvimento de softwares com metodologias ágeis. Revista de Ciência e Tecnologia, 2(2), 01-23. https://revista.ufrr.br/rct/article/download/2681/2000

Signori, G. G., Martins, A. R. Q., Silva, M., Jr., Kalil, F., \& Capelari, M. R. (2014, setembro). Startup e inovação: inovando na forma de pensar e decretando o fim das velhas ideias. Anais do Seminário Nacional de Parques Tecnológicos e Incubadoras de Empresas, Belém, PA, Brasil, 23. https://www.imed.edu.br/Uploads/amiltomrodrigodequadrosmartins_moacirdasilvajunior(\%C3\%A1r_ea1).pdf

Silva, E. C., \& Lovato, L. A. (2016). Framework Scrum: eficiência em projetos de software. Revista de Gestão e Projetos, 7(2), 01-15. https://doi.org/10.5585/gep.v7i2.330

Silva, R. T. (2011). Aplicação da metodologia Scrum para gestão de projetos na indústria naval (Trabalho de conclusão de curso). Universidade Federal do Ceará, Fortaleza, CE, Brasil. http://repositorio.ufc.br/bitstream/riufc/35695/1/2011_tcc_rtsilva.pdf

Silva, S. E. P., Calado, R. D., Silva, M. B., \& Nascimento, M. A. (2013). Lean startup applied in healthcare: a viable methodology for continuous improvement in the development of new products and services. IFAC Conference on Management and Control of Production and Logistics, 6(24), 295-299. http://dx.doi.org/10.3182/20130911-3-BR-3021.00054

Silveira, D. W. A. (2012). Ferramenta para apoio à estimativa baseada em Planning Poker utilizando a metodologia Scrum (Trabalho de conclusão de curso). Universidade Federal de Pernambuco. https://www.cin.ufpe.br/ tg/2012-1/dwas.pdf

Soares, M. S. (2004). Comparação entre Metodologias Ágeis e Tradicionais para o Desenvolvimento de Software. Journal of Computer Science, 27(2), 01-06. http://infocomp.dcc.ufla.br/index.php/infocomp/article/view/6810

Souza, D. R. (2014). Implantação da metodologia Scrum em um ambiente de desenvolvimento (Trabalho de conclusão de curso). Universidade Federal de Santa Catarina, Araranguá, SC, Brasil. https://repositorio.ufsc.br/xmlui/bitstream/handle/123456789/130043/TCC\%20Final.pdf?sequence=1\&isAllowed=y>

Sutherland, J. (2014). Scrum: a arte de fazer o dobro do trabalho na metade do tempo: LeYa.

Vargas, R. V. (2005). Gerenciamento de Projetos, estabelecendo diferenciais competitivos (6a ed.) Brasport.

Xavier, R. L. F. (2017). Metodologias tradicionais e metodologias ágeis: uma análise comparativa entre Rational Unified Process (RUP) e Scrum (Framework estruturado) (Trabalho de conclusão de curso). Universidade Estadual do Norte do Paraná, Bandeirantes, PR, Brasil. http://200.201.11.152/bitstream/handle/123456789/221/METODOLOGIAS\%20TRADICIONAIS\%20E\%20METODOLOGIAS\%20ÁGEIS\%20UMA\%20AN ÁLISE\%20COMPARATIVA\%20ENTRE\%20RATIONAL\%20UNIFIED\%20PROCESS\%20\%28RUP\%29\%20E\%20Scrum\%20\%28FRAM 1.pdf?sequence $=1 \&$ is Allowed $=\mathrm{y}$

Yin, R. K. (2001). Estudo de caso: planejamento e métodos. (2a ed.), Bookman. (Obra original publicada em 1984) 